\title{
Motivation for participation in sports among Brazilian adults: National Household Sample Survey - 2015
}

\author{
Motivação para participação em esportes entre adultos brasileiros: \\ Pesquisa Nacional de Amostras de Domicílios - 2015
}

\author{
Andrea Wendt (https://orcid.org/0000-0002-4640-2254) ${ }^{1}$ \\ Luiza Isnardi Cardoso Ricardo (https://orcid.org/0000-0002-1244-4501) ${ }^{1}$ \\ Caroline dos Santos Costa (https://orcid.org/0000-0002-3522-1546) ${ }^{2}$ \\ Francine dos Santos Costa (https://orcid.org/0000-0001-9558-937X) ${ }^{3}$ \\ Thaynã Ramos Flores (https://orcid.org/0000-0003-0098-1681) ${ }^{1}$ \\ Rosália Garcia Neves (https://orcid.org/0000-0001-6798-9130) ${ }^{4}$ \\ Grégore Iven Mielke (https://orcid.org/0000-0003-4568-6440) ${ }^{5}$
}

${ }^{1}$ Programa de Pós-

Graduação em

Epidemiologia,

Universidade Federal

de Pelotas. R. Marechal

Deodoro $1160,3^{\circ}$ andar.

96020-220 Pelotas RS Brasil.

andreatwendt@gmail.com

${ }^{2}$ Programa de Pós-

Graduação em Nutrição em

Saúde Pública, Faculdade de

Saúde Pública, Universidade

de São Paulo. São Paulo SP

Brasil.

${ }^{3}$ Curso de Odontologia,

Universidade do Vale do

Taquari (UNIVATES).

Taquari RS Brasil.

${ }^{4}$ Secretaria Estadual de

Saúde. Porto Alegre RS

Brasil.

${ }^{5}$ School of Human

Movement and Nutrition

Sciences, The University

of Queensland. Brisbane

Australia.

\begin{abstract}
This article aims to describe the reasons for sport participation in the Brazilian adult population according to gender, age and schooling level. This is a cross-sectional study with data from a National Household Sample Survey - 2015. The reasons to practice or not practice sports in the previous year were obtained by questionnaire with predetermined answer options. All analyses were performed in Stata 12.1 and stratified by gender. The prevalence of sports participation for men and women were $31.7 \%$ and $16.9 \%$, respectively. The most frequent reasons for sports participation among men were: having fun, quality of life and performance. Among women, the most frequent reasons were: quality of life, performance and medical recommendation. Regarding reasons for not practicing sports, the most reported ones were: lack of time (38.8\% for men and $37.8 \%$ for women), not enjoying (34.8\% for men and $35.3 \%$ for women) and health problem (20.3\% for men and $17.9 \%$ for women). The study findings showed the most frequent reasons for sport participation in Brazil. Understanding these reasons and how they affect different age ranges and educational levels may contribute to improve strategic planning to promote sports in middle-income countries.

Key words Physical activity, Cross-sectional study, Population-based, Exercise
\end{abstract}

Resumo O objetivo deste artigo é descrever os motivos para participação esportiva da população adulta brasileira de acordo com sexo, idade e escolaridade. Trata-se de um estudo transversal com dados da Pesquisa Nacional por Amostras de Domicílios - 2015. Os motivos para praticar ou não esportes no ano anterior foram obtidos por questionário com respostas pré-determinadas. Todas as análises foram realizadas no software Stata 12.1 e estratificadas por gênero. As prevalências de participação em esportes para homens e mulheres foram $31,7 \%$ e 16,9\%, respectivamente. Entre os homens, os motivos mais frequentes para participação em esportes foram: diversão, qualidade de vida e desempenho. Entre as mulheres, os motivos mais frequentes foram: qualidade de vida, desempenho e indicação médica. Quanto aos motivos para não praticar esportes, os mais relatados foram: falta de tempo (38,8\% para os homens e $37,8 \%$ para as mulheres), não gostar (34,8\% para os homens e $35,3 \%$ para as mulheres) e problemas de saúde (20,3\% para os homens e 17,9\% para as mulheres). O estudo mostrou os motivos mais frequentes para a prática esportiva no Brasil. Compreender esses motivos e como eles são influenciados pela idade e por nível de educação pode contribuir para melhorar estratégias para promover o esporte em países de renda média.

Palavras-chave Atividade física, Estudo transversal, Base populacional, Exercício 


\section{Introduction}

Physical inactivity is one of the leading causes of mortality worldwide ${ }^{1}$, with nearly one in four adults not meeting the current physical activity guidelines ${ }^{2}$. Estimates from the most recent National Health Survey, showed that $46 \%$ of Brazilian adults are physically inactive in all domains (leisure, transportation and occupational physical activity) $)^{3}$. This scenario is even worse in specific population groups such as women, elderly and people from low socioeconomic backgrounds 4 .

Sports is a subset of physical activity, which has been suggested as a promising strategy to improve population levels of physical activity and health ${ }^{5}$, since it brings together well documented physiological and psychological benefits of exercise making exercise more pleasant ${ }^{6,7}$. Regarding sports participation in Brazil, estimates showed football as the most frequent practice in the country $(7.2 \%)$, and other sports present irrelevant prevalence compared to walking or exercise in general ${ }^{8}$. This may reinforce the need for a more detailed understanding of active lifestyle promotion via sports participation in the country.

A recent systematic review has shown that health benefits promoted by participating in recreational sports may vary according to specific modalities 9 . In this review of 22 prospective studies, there was moderate to strong evidence that running and football were associated with higher fitness and a lower resting heart rate, while football was associated with lower adiposity. However, due to the paucity of studies and weak study designs in the existing literature, evidence of associations between other sports and health outcomes were mostly inconclusive $e^{9,10}$.

In this context, several factors have been indicated as determinants for physical activity among adults, such as psychological, sociocultural, environmental and health related ${ }^{11}$. A study with Malaysian volunteers verified differences in motivation to sports participation. Women reported aestheticsand physical fitness as the main reasons to practice sports, while men reported competition/ego and mastery. Regarding age differences in reasons to practice, the study showed that young adults usually reported affiliation, mastery, and enjoyment as reasons to practice, while older individuals usually reported psychological condition ${ }^{12}$. Another study with Slovenian university students also showed gender difference in sports participation motivation with men reporting en- joyment, challenge, social recognition, affiliation, competition and strength, while women reported stress and weight management, revitalisation, health problems avoidance, positive health, appearance and agility ${ }^{13}$. These studies show the difference between subgroups of population regarding motivation to sports participation according to gender and age. Other variable that could influence sports participation is education level, as proxy of socioeconomic position. Studies evaluating physical activity has shown this variable as an import aspect to be evaluated ${ }^{14,15}$.

Sports participation may vary according to regions and cultures ${ }^{5}$, gender, age and education. Thus, the focus of physical activity and sports promotion needs to be adapted to the preferences, barriers and specificities of each country. However, there has been little research investigating determinants and barriers of recreational sports participation, particularly in low and middle-income countries and at populational level. Therefore, the present study aims to describe the motivations for participation and non-participation in recreational sports among Brazilian adults.

\section{Materials and methods}

Data from the National Household Sample Survey (PNAD) carried out in 2015 were analysed. The PNAD is a representative survey which investigated general characteristics of the Brazilian population, including education, occupational activities, income, and home environment in an annual basis. A probabilistic sample was obtained using three selection stages: primary (cities), secondary (census tracts) and tertiary units (households). This study used public domain data without identification of the subjects. Furthermore, PNAD is part of the current Brazilian surveillance system and is exempted of ethical clearance according to the Resolution of the Brazilian National Health Council 466, 12 December $2012^{16}$.

In each household, a questionnaire including sociodemographic and behavioural questions was applied to one randomly selected resident over 15 years old. Further details on the sampling process were published elsewhere ${ }^{17}$.

Participation in recreational sports in the previous 12 months was assessed using the following question: "In the previous 12 months, have you done any sports during your leisure time?" Those who reported participation in sports in the pre- 
vious period were also asked about the main reason for their engagement. The subject was supposed to choose one reason among the following: a) medical recommendation; b) performance; c) quality of life; d) enjoys competing; e) having fun; f) socialize and meeting with friends or making new friends; g) other reason. Those who did not report sports practice were also asked the main reason for not doing so choosing one reason among the following: a) lack of time; b) health related problem or advanced age; c) financial problems; d) lack of proper accessible sports facilities; e) lack of companionship for practicing sports; f) not enjoying; g) other reason.

Initially, descriptive analyses were conducted to estimate not only the prevalence of participation in recreational sports but also the $95 \%$ confidence interval $(95 \% \mathrm{CI})$ in each gender according to age groups $(15-19 ; 20-29 ; 30-39 ; 40-49$; 50-59; 60+ years old) and education (none; incomplete primary level; complete primary level; secondary complete level; graduation). Secondly, sports participation reasons prevalence and 95\% $\mathrm{CI}$ adjusted for age and education were calculated. Lastly, the associations between age and education with the three more frequent reasons for participation and non-participation in sports were investigated using Poisson regression models with adjustment for age and education. All analyses were conducted in Stata 12.1 using the svy command to consider sample weight.

\section{Results}

The total sample was made up of 71,142 individuals aged 15 years or older ( $52.2 \%$ men). Around $31 \%$ of men and $16 \%$ of women reported participation in recreational sports in the previous 12 months. The prevalence of sports participation was higher in men than women in all age groups except in older population subgroups. In both genders, the prevalence of sports participation was higher in younger individuals and in those with higher educational levels in comparison to their counterparts (Table 1).

\section{Reasons for participation in recreational sports}

Graphic 1 shows the prevalence of reasons for sports participation in the previous 12 months. In men, the most reported reasons were having fun $(37.8 \%)$, quality of life $(20.1 \%)$ and performance $(18.3 \%)$. Among women, the most fre- quent reasons were quality of life (38.5\%), performance $(22.5 \%)$ and medical recommendation $(18.6 \%)$.

Table 2 presents the adjusted analyses between age and education with the main reasons for participation in sports in the previous 12 months. Among men, sports participation aiming at performance and quality of life were positively associated with educational level. The prevalence of sports participation aiming at quality of life increased according to age. As age and educational level increased, sports participation for fun decreased.

Among women, sports participation aiming at performance was negatively associated with age and positively related to educational level (Table 2). The sports participation aiming at quality of life was $86 \%$ higher among women aged 50-59 in comparison to those aged 15-19, and this outcome increased according to educational level. Regarding sports participation as medical recommendation, the prevalence was nearly 12 times higher in those women aged 60 years or older than those aged 15-19 years old and this outcome was lower among better educated women.

\section{Reasons for not having practiced sport}

The three main reasons for non-participation in sports in the previous 12 months were lack of time (38.8\% in men; $37.8 \%$ in women), not enjoying sports practice or not desiring to practice sports $(34.8 \%$ in men; $35.3 \%$ in women) and health problems $(20.3 \%$ in men; $17.9 \%$ in women) (Graphic 2).

Table 3 describes reasons for non-participation in sports. Among men, the prevalence of reporting lack of time was 1.96 times higher among those aged 30-39 years in comparison to those aged 15-19 years, and this outcome increased according to education level. As the prevalence of reporting health problems increased according to age, educational level decreased. The reason for not enjoying sports practice decreased according to age and educational level.

Among women, lack of time was $80 \%$ more prevalent in 30-39 years old individuals, when compared to those aged 15-19 years, and this prevalence increased with education. The reason health problem increased according to age but decreased according to education. Not enjoying sports practice was inversely associated with age and education. 
Table 1. Description of the sample and sports participation according to age and education and stratified by gender. Individuals aged 15 years and over (total n: 71,142).

\begin{tabular}{|c|c|c|c|c|}
\hline & \multicolumn{2}{|c|}{ Men (n: 32,843) } & \multicolumn{2}{|c|}{ Women (n: 38,299) } \\
\hline & Sample & Sport participation & Sample & Sport participation \\
\hline & $\%$ & $\%(95 \% \mathrm{CI})$ & $\%$ & $\%(95 \% \mathrm{CI})$ \\
\hline \multicolumn{5}{|l|}{ Age } \\
\hline $15-19$ & 11.5 & $58.1(55.9 ; 60.2)$ & 10.1 & $22.6(20.8 ; 24.4)$ \\
\hline $20-29$ & 20.0 & $46.1(44.6 ; 47.7)$ & 18.0 & $18.0(16.9 ; 19.1)$ \\
\hline $30-39$ & 19.8 & $34.2(32.9 ; 35.6)$ & 19.7 & $17.9(16.9 ; 18.9)$ \\
\hline $40-49$ & 17.5 & $22.7(21.5 ; 24.0)$ & 17.5 & $16.1(15.1 ; 17.2)$ \\
\hline $50-59$ & 14.5 & $18.4(17.1 ; 19.7)$ & 15.2 & $16.6(15.5 ; 17.8)$ \\
\hline $60+$ & 16.7 & $13.9(12.8 ; 15.0)$ & 19.5 & $13.0(12.1 ; 13.9)$ \\
\hline \multicolumn{5}{|l|}{ Education } \\
\hline No instruction & 8.4 & $9.1(7.8 ; 10.3)$ & 8.2 & $6.2(5.3 ; 7.2)$ \\
\hline Incomplete primary level & 30.8 & $23.2(22.1 ; 24.2)$ & 27.7 & $11.9(11.1 ; 12.6)$ \\
\hline Complete primary level & 19.8 & $38.2(36.7 ; 39.7)$ & 17.9 & $16.5(15.4 ; 17.6)$ \\
\hline Secondary level & 30.8 & $39.0(37.8 ; 40.2)$ & 32.9 & $19.2(18.3 ; 20.0)$ \\
\hline Graduation & 10.2 & $42.3(40.2 ; 44.3)$ & 13.3 & $30.0(28.5 ; 31.5)$ \\
\hline Total & 100 & $31.7(31.0 ; 32.3)$ & 100 & $16.9(16.5 ; 17.4)$ \\
\hline
\end{tabular}

${ }^{\star} \mathrm{P}$ value for trend

Source: PNAD, 2015.

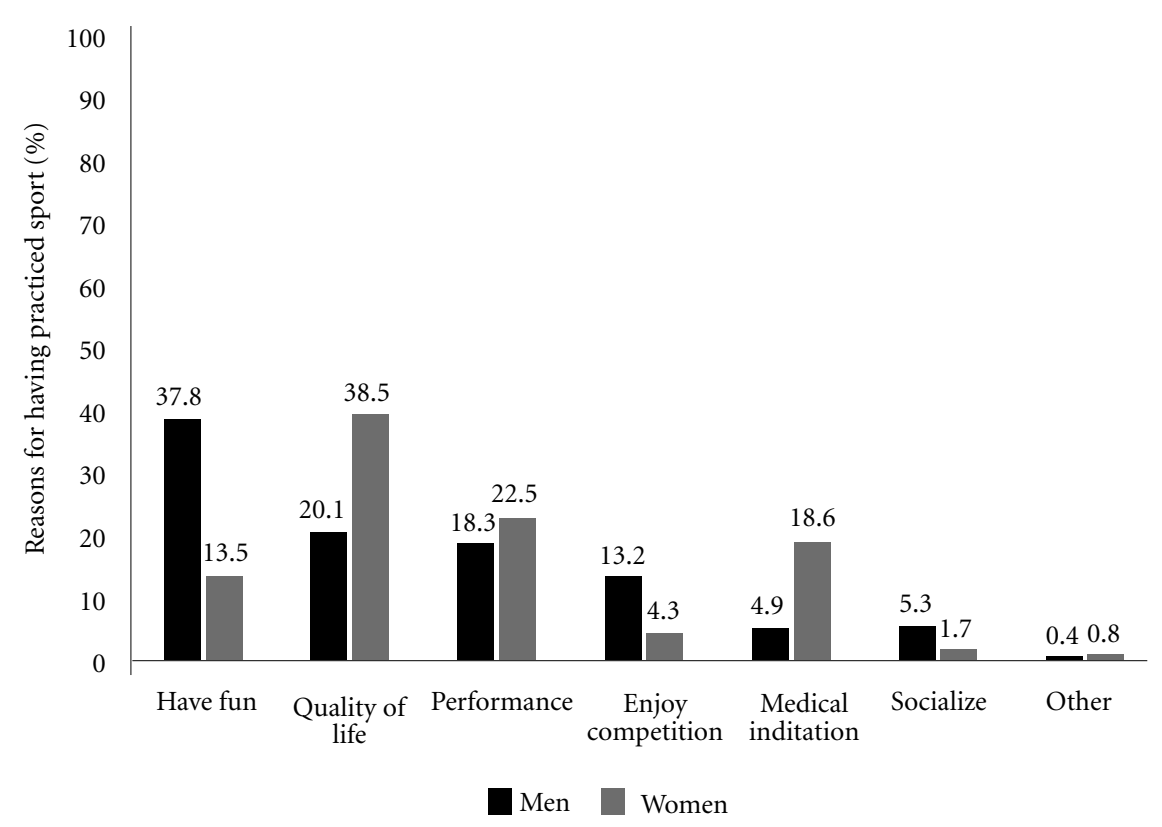

Graphic 1. Prevalence of the reasons for having practiced sport in the past year according to gender (n men: 10,080; n women: 6,550).

Source: PNAD, Brazil, 2015.

\section{Discussion}

This study has shown that $31.7 \%$ of men and $16.9 \%$ of women reported sports participation in Brazil. For both genders, sports participation decreased with age but increased with education. The most frequent reasons for sports participation for men were fun $(37.8 \%)$, quality of life 
Table 2. Adjusted analysis of the main reasons for practicing sports in the past year for men and women according to age and education.

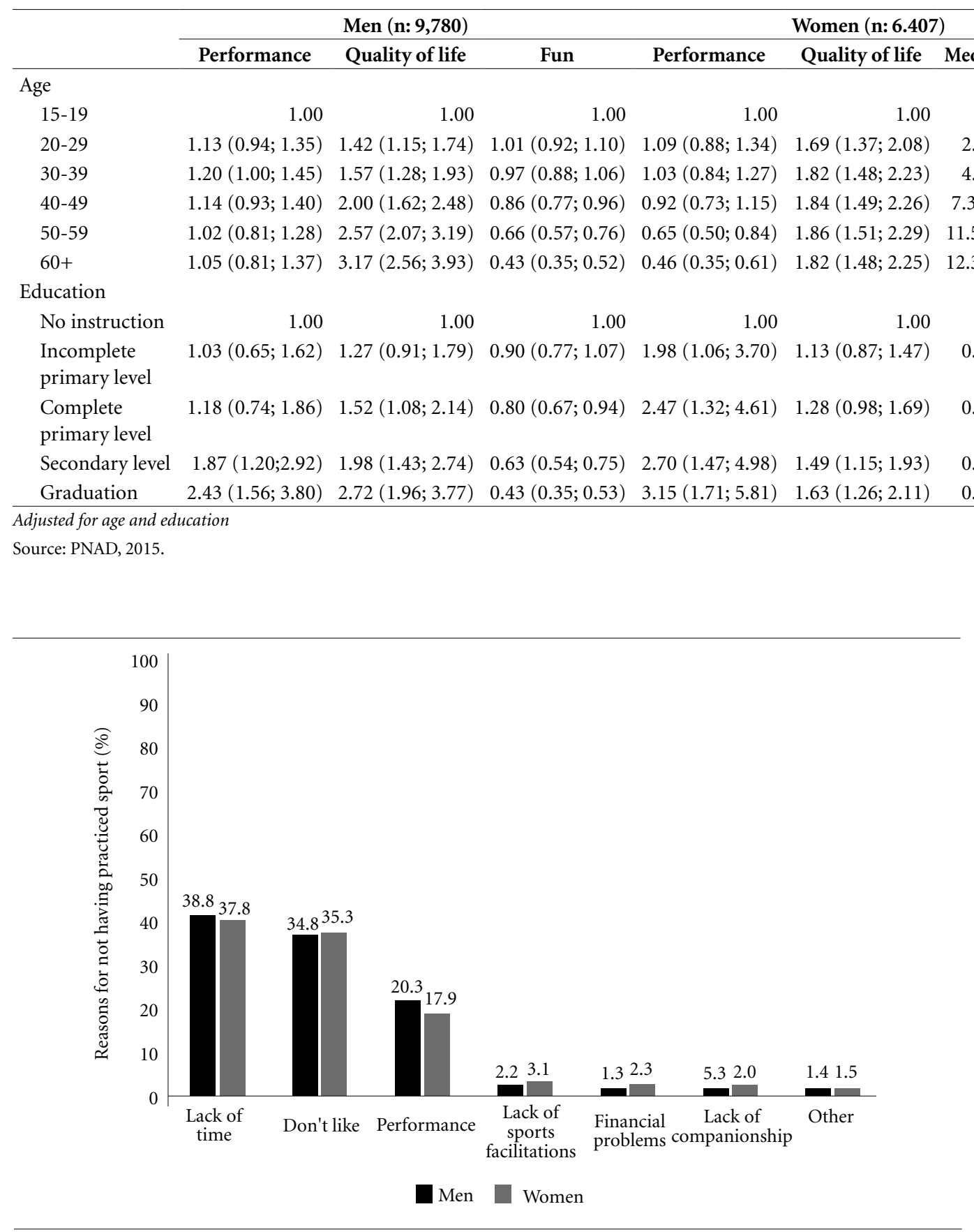

Graphic 2. Prevalence of the reasons for not having practiced sports in the past year according to gender (n men: 22,763; n women: 31,749).

Source: PNAD, Brazil, 2015.

(20.1\%) and physical performance (18.3\%). In women, the most reported reasons were quality of life $(38.5 \%)$, physical performance $(22.5 \%)$ and medical indication (18.6\%). The reasons for not practicing were similar for men and women. The most reported reason for not practicing was lack of time (about 38\% for both genders). The literature about sports participation remains 
Table 3. Adjusted analysis of the main reasons for not having practiced sport in the past year, stratified by gender, in individuals aged 15 years or over

\begin{tabular}{|c|c|c|c|c|c|c|}
\hline & \multicolumn{3}{|c|}{ Men (n: 21,959) } & \multicolumn{3}{|c|}{ Women (n: 30,747) } \\
\hline & Lack of time & Health problem & Not enjoy & Lack of time & Health problem & Not enjoy \\
\hline \multicolumn{7}{|l|}{ Age } \\
\hline $15-19$ & 1.00 & 1.00 & 1.00 & 1.00 & 1.00 & 1.00 \\
\hline $20-29$ & $1.72(1.52 ; 1.95)$ & $1.30(0.93 ; 1.82)$ & $0.75(0.69 ; 0.82)$ & $1.59(1.46 ; 1.74)$ & $0.98(0.72 ; 1.34)$ & $0.77(0.72 ; 0.82)$ \\
\hline $30-39$ & $1.96(1.73 ; 2.21)$ & $1.74(1.27 ; 2.38)$ & $0.63(0.58 ; 0.68)$ & $1.80(1.65 ; 1.96)$ & $1.33(1.00 ; 1.76)$ & $0.67(0.62 ; 0.71)$ \\
\hline $40-49$ & $1.88(1.67 ; 2.13)$ & $2.62(1.93 ; 3.55)$ & $0.63(0.58 ; 0.69)$ & $1.66(1.52 ; 1.82)$ & $2.95(2.25 ; 3.85)$ & $0.67(0.63 ; 0.72)$ \\
\hline $50-59$ & $1.58(1.39 ; 1.79)$ & $4.13(3.06 ; 5.58)$ & $0.63(0.58 ; 0.69)$ & $1.35(1.23 ; 1.48)$ & $5.43(4.19 ; 7.04)$ & $0.66(0.61 ; 0.70)$ \\
\hline $60+$ & $0.70(0.61 ; 0.81)$ & $8.28(6.15 ; 11.14)$ & $0.55(0.50 ; 0.60)$ & $0.63(0.57 ; 0.71)$ & $11.02(8.53 ; 14.23)$ & $0.49(0.46 ; 0.53)$ \\
\hline \multicolumn{7}{|l|}{ Education } \\
\hline No instruction & 1.00 & 1.00 & 1.00 & 1.00 & 1.00 & 1.00 \\
\hline $\begin{array}{l}\text { Incomplete } \\
\text { primary level }\end{array}$ & $1.59(1.43 ; 1.76)$ & $0.81(0.75 ; 0.86)$ & $0.94(0.87 ; 1.01)$ & $1.64(1.47 ; 1.84)$ & $0.82(0.77 ; 0.87)$ & $0.94(0.87 ; 1.00)$ \\
\hline $\begin{array}{l}\text { Complete } \\
\text { primary level }\end{array}$ & $1.87(1.67 ; 2.08)$ & $0.67(0.60 ; 0.74)$ & $0.87(0.80 ; 0.95)$ & $1.96(1.75 ; 2.21)$ & $0.65(0.59 ; 0.72)$ & $0.90(0.83 ; 0.97)$ \\
\hline Secondary level & $2.14(1.93 ; 2.37)$ & $0.53(0.48 ; 0.59)$ & $0.79(0.72 ; 0.85)$ & $2.23(1.99 ; 2.49)$ & $0.52(0.47 ; 0.57)$ & $0.79(0.73 ; 0.85)$ \\
\hline Graduation & $2.32(2.08 ; 2.59)$ & $0.41(0.35 ; 0.48)$ & $0.75(0.68 ; 0.83)$ & $2.44(2.18 ; 2.73)$ & $0.46(0.41 ; 0.52)$ & $0.79(0.72 ; 0.86)$ \\
\hline
\end{tabular}

scarce and the comparison with other studies is difficultbecause most studies evaluate physical activity and not sports participation. Furthermore, the few studies about sports are based in specific or convenience samples with specific instruments. Thus, explanations are sometimes based on physical activity literature, which is not the same literature for sports, however literature from the physical activity area may help to raise hypotheses to explain associations in sports participation.

The prevalence of sports participation varied by gender and was higher in younger and better-educated individuals, corroborating with other studies about physical activity ${ }^{14}$. One of the aspects which may influence gender differences is modalities. Sa et al. (2014) have shown that the prevalence of leisure-time walking was 30\% higher in women than in men, whereas the prevalence of football was almost $40 \%$ higher in men than in women ${ }^{8}$. In our study, the prevalence of sports participation for men was $58.1 \%$ in the youngest group and $13.9 \%$ in the oldest group. The difference among age groups was slightly smaller in women than in men. Among the youngest group of women, $23 \%$ reported sports participation, whereas this proportion was $13 \%$ among the oldest group. These findings are similar toa study about leisure time physical activit- yin a national sample in Brazil (15 years or older) with marked decrease in exercise participation among men ${ }^{4}$. The study identified a prevalence of leisure physical activity two times higher for men compared to women in the youngest group. On the other hand, after 45 years, no difference was found between men and women ${ }^{4}$. Further studies are needed to understand why the prevalence of physical activity and sports decreases abruptly with age in men, particularly in low-middle income countries.

The reasons for sports participation are in accordance with patterns observed for leisure-time physical activity. Data from a nationwide health survey conducted in Brazil in 2013 showed that men, individuals with better education and younger individuals were the most active at leisure-time ${ }^{18}$. The study also shows that the magnitude of this association changes across the country and was more pronounced in the North ${ }^{3}$. A study about physical activity preferences in Australia showed that young people prefer teambased activities and with competition ${ }^{19}$, features which are intrinsic to sport-based activities. Thus, it is likely that young people choose sports practice more frequently as their leisure-time physical activity option.

So far, only one study has investigated reasons for sports participation in Brazil, in a sam- 
ple of 100 men and 138 women from a northern city in the country. Despite the sample size, it was observed that men were more motived for social experience with sports; young adults for enjoyment and improvement in appearance, and more educated individuals were motivated for health and fitness ${ }^{15}$.

In general, women practice less physical activity as showed in a national survey with adults ${ }^{4}$, and the possible reasons are more related to specific goals, such as health, well-being, and aesthetics. Women have reported medical recommendation as one of the main reasons for practicing sports, and this may be explained by the fact that they use health care services more frequently than men ${ }^{20}$. Beartakis et al. showed that women visit primary care and diagnostic services more frequently than $\operatorname{men}^{20}$, resulting in orientation to improve health, including the practice of sports or physical activity ${ }^{21}$.

Overall, sports participation for quality of life was more reported in individuals who were older and from higher schooling levels. This association might reflect higher knowledge and information about sport and exercise benefits acquired with higher education. Older adults also search for more quality of life, well-being and socialization activities intrinsic to some sports compared to younger adults ${ }^{22}$.

The reasons for not practicing sports were similar between men and women. The most frequent reason was lack of time, corroborating with previous studies ${ }^{21}$. This reason was more frequent not only in the 20-59-year-old group but also in individuals from higher schooling levels, which might be related to work responsibilities in these groups ${ }^{23}$.

Over $35 \%$ of the sample reported that they did not enjoy sports. This reason was more often reported by younger and lower educated individuals. Good and early experiences with exercise may contribute to a higher level of physical activity in adult life ${ }^{24}$.

The main limitation of this study is information on sports participation. The used questionnaire does not specify the frequency for practicing sports in the previous year, which can implicate in misclassification. Thus, sports participation in our study includes both individuals with regular practice and sporadic practice. This limitation may result in overestimation of the presented prevalence.
The strength of this work is the availability of information about sports in a representative sample from a middle-high income country. In contrast to the research in the physical activity area, sports information is still scarce in a national context, and the majority of the studies with sports are carried out in high-income countries or evaluate convenience samples.

\section{Conclusion}

Our study presented the most frequent reasons for sports participation in Brazil according to gender, age, and education. Sports interventions should be focused on barriers and motivation of the targeted population. Thus, this study may help to understand the reasons for practicing and not practicing sports associated with different age ranges and educational levels. This study may also contribute to better planning of strategies to promote sports and improve interventions in middle-income countries.

\section{Collaborators}

A Wendt, SC Costa and LIC Ricardo conceived of the presented idea. A Wendt performed the data analysis. A Wendt, SC Costa, LIC Ricardo, FS Costa, TR Flores and RG Neves carried out data interpretation and wrote the paper. Mielke GI supervised the findings of this work. All authors discussed the results and contributed to the final manuscript.

\section{Acknowledgements}

Ms. Andrea Wendt, Ms. Luiza Ricardo, Ms. Caroline Costa, Ms. Francine Costa, Ms. Thaynã Flores and Ms. Rosália Neves were funded by CAPES or CNPq PhD scholarships. 


\section{References}

1. Lee IM, Skerrett PJ. Physical activity and all-cause mortality: what is the dose-response relation? Med Sci Sports Exerc 2001; 33(Suppl.6):S459-S471; discussion S93-S94.

2. Sallis JF, Bull F, Guthold R, Heath GW, Inoue S, Kelly P, Oyeyemi AL, Perez LG, Richards J, Hallal PC. Progress in physical activity over the Olympic quadrennium. Lancet 2016; 388(10051):1325-1336.

3. Mielke GI, Hallal PC, Rodrigues GBA, Szwarcwald CL, Santos FV, Malta DC. Prática de atividade física e hábito de assistir à televisão entre adultos no Brasil: Pesquisa Nacional de Saúde 2013. Epidemiol Serv Saude 2015; 24(2):277-286.

4. Silva ICM, Mielke GI, Bertoldi AD, Arrais PSD, Luiza VL, Mengue SS, Hallal PC. Overall and leisure-time physical activity among Brazilian adults: National Survey Based on the Global Physical Activity Questionnaire. J Phys Act Health 2018; 15(3):212-218.

5. Khan KM, Thompson AM, Blair SN, Sallis JF, Powell KE, Bull FC, Bauman AE. Sport and exercise as contributors to the health of nations. Lancet 2012; 380(9836):59-64.

6. Chalip L. Toward a distinctive sport management discipline. J Sport Manage 2006; 20(1):1-21.

7. Leipert BD, Plunkett R, Meagher-Stewart D, Scruby L, Mair H, Wamsley KB. "I can't imagine my life without it!" Curling and health promotion: a photovoice study. Can J Nurs Res 2011; 43(1):60-78.

8. Sa TH, Garcia LM, Claro RM. Frequency, distribution and time trends of types of leisure-time physical activity in Brazil, 2006-2012. Int J Public Health 2014; 59(6):975-982.

9. Oja P, Kelly P, Pedisic Z, Titze S, Bauman AE, Foster C, Hamer M, Hillsdon M, Stamatakis E. Associations of specific types of sports and exercise with all-cause and cardiovascular-disease mortality: a cohort study of 80 306 British adults. Br J Sports Med 2017; 51(10):812817.

10. Oja P, Titze S, Kokko S, Kujala UM, Heinonen A, Kelly P, Koski P, Foster C. Health benefits of different sport disciplines for adults: systematic review of observational and intervention studies with meta-analysis. $\mathrm{Br} \mathrm{J}$ Sports Med 2015; 49(7):434-440.

11. Kelly S, Martin S, Kuhn I, Cowan A, Brayne C, Lafortune L. Barriers and facilitators to the uptake and maintenance of healthy behaviours by people at mid-life: a rapid systematic review. PloS one 2016; 11(1):e0145074.

12. Molanorouzi K, Khoo S, Morris T. Motives for adult participation in physical activity: type of activity, age, and gender. BMC public health 2015;15:66.

13. Cerar K, Kondric M, Ochiana N, Sindik J. Exercise participation motives and engaging in sports activity among University of Ljubljana Students. Open Access Maced J Med Sci 2017; 5(6):794-9.
14. Bauman AE, Reis RS, Sallis JF, Wells JC, Loos RJ, Martin BW. Correlates of physical activity: why are some people physically active and others not? Lancet 2012; 380(9838):258-271.

15. Bastos AA, Salguero A, Gonzalez-Boto R, Marquez S. Motives for participation in physical activity by Brazilian adults. Percept Mot Skills 2006; 102(2):358-367.

16. Brasil. Ministério da Saúde. Resolução no 466, de 12 de dezembro de 2012. Diário Oficial da União 2012; $13 \mathrm{dez}$.

17. Instituto Brasileiro de Geografia e Estatística (IBGE). National Household Sample Survey - PNAD [Internet]. [cited 2020 Apr 1]. Available from: https://www. ibge.gov.br/en/statistics/multi-domain/science-technology-and-innovation/18079-brazil-volume-pnad1. $\mathrm{html} ?=\& \mathrm{t}=\mathrm{o}$-que-e.

18. Mielke GI, Malta DC, Sa GB, Reis RS, Hallal PC. Regional differences and correlates of leisure time physical activity in Brazil: results from the Brazilian National Health Survey - 2013. Rev Bras Epidemiol 2015; 18(Suppl. 2):158-169.

19. Burton NW, Khan A, Brown WJ. How, where and with whom? Physical activity context preferences of three adult groups at risk of inactivity. Br J Sports Med 2012; 46(16):1125-1131.

20. Bertakis KD, Azari R, Helms LJ, Callahan EJ, Robbins JA. Gender differences in the utilization of health care services. J Fam Pract 2000; 49(2):147-152.

21. Bowles HR, Morrow Jr. JR., Leonard BL, Hawkins M, Couzelis PM. The association between physical activity behavior and commonly reported barriers in a worksite population. Res Q Exerc Sport 2002; 73(4):464-470.

22. Netuveli G, Wiggins RD, Hildon Z, Montgomery SM, Blane D. Quality of life at older ages: evidence from the English longitudinal study of aging (wave 1). J Epidemiol Community Health 2006; 60(4):357-363.

23. Burton NW, Turrell G. Occupation, hours worked, and leisure-time physical activity. Prev Med 2000; 31(6):673-681.

24. Reichert FF, Barros AJ, Domingues MR, Hallal PC. The role of perceived personal barriers to engagement in leisure-time physical activity. Am J Public Health 2007; 97(3):515-519.

Article submitted 20/12/2019

Approved 24/04/2020

Final version submitted $26 / 04 / 2020$

Chief editors: Romeu Gomes, Antônio Augusto Moura da Silva 